\title{
Article \\ Acquisition and User Behavior in Online Science Laboratories before and during the COVID-19 Pandemic
}

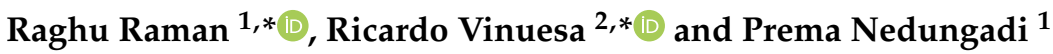 \\ 1 Amrita School of Engineering, Amritapuri, Amrita Vishwa Vidyapeetham, Kerala 690525, India; \\ prema@amrita.edu \\ 2 Engineering Mechanics, KTH Royal Institute of Technology, SE-10044 Stockholm, Sweden \\ * Correspondence: raghu@amrita.edu (R.R.); rvinuesa@mech.kth.se (R.V.)
}

check for updates

Citation: Raman, R.; Vinuesa, R.; Nedungadi, P. Acquisition and User Behavior in Online Science Laboratories before and during the COVID-19 Pandemic. Multimodal Technol. Interact. 2021, 5, 46. https:// doi.org $/ 10.3390 / \mathrm{mti} 5080046$

Academic Editor: Mu-Chun Su

Received: 16 June 2021

Accepted: 6 August 2021

Published: 16 August 2021

Publisher's Note: MDPI stays neutral with regard to jurisdictional claims in published maps and institutional affiliations.

Copyright: (c) 2021 by the authors. Licensee MDPI, Basel, Switzerland. This article is an open access article distributed under the terms and conditions of the Creative Commons Attribution (CC BY) license (https:/ / creativecommons.org/licenses/by/ $4.0 /)$.

\begin{abstract}
The COVID-19 pandemic has resulted in the closure of schools at every level, globally, forcing education to move online. Meeting the needs of students online for Science Lab classes, in particular, is a challenge since the physical labs are not available to the teachers or students. OLabs is a virtual Science Lab providing a complete learning environment of theory, experimental procedures, videos, animations, simulations, and assessments that capture real lab experiences with the relevant pedagogy. This study looks at the acquisition and behaviors of users, on the OLabs platform, during pre and COVID-19 times. Using Google Analytics, we observe that, during the pandemic time, users increasingly adopted OLabs as a new learning pedagogy for performing experiments as indicated by parameters like the number of users; the number of unique pages viewed per session; time spent on viewing content; bounce rate; and preference for content types such as theory, simulations, videos, and animations.
\end{abstract}

Keywords: online laboratories; virtual laboratories; COVID-19; simulations; science; school

\section{Introduction}

The recent COVID-19 crisis has impacted every social sector, and education is no exception. Throughout the world, schools have shifted to online classes. The long-term socioeconomic impacts of COVID-19 on education are yet to be known. However, this large-scale obstruction to the established teaching-learning paradigm is likely to affect more than 1.6 billion learners of various ages. The World Bank projects that through the lifetime of these students, the monetary cost of this shutdown in terms of lost lifetime earnings could be up to USD 10 trillion [1]. UNESCO has claimed that the pandemic has disrupted the learning of 9 out of 10 students globally [2]. The closure is also more likely to affect disadvantaged communities and female students more acutely, with many being forced out of education as family income levels drop due to the pandemic [3]. The adverse effects are likely to be more pronounced in underdeveloped and developing countries where the education system is less capable of handling this sudden change. In addition, high school students are more likely to be affected given the higher chances of dropping out due to financial vulnerability and the greater challenges involved in learning more complex topics [4].

India, with more than 320 million students in school, is no exception to the challenges posed by the pandemic. Education in India is further complicated with multiple languages of instruction, and many state and national boards controlling the syllabi in various schools. In general, the approach has been to migrate to online education throughout the country. This has largely been necessitated by the nationwide lockdown implemented to minimize the spread of COVID-19. While the country has a relatively high mobile penetration, providing universal access to online education has been challenging and has been addressed with varying degrees of success by various states [5]. Despite these efforts, students, especially those in classes 9 to 12 , are affected negatively by this shift. 
While theoretical topics can be taught online with a certain degree of efficiency, conducting laboratory experiments poses additional challenges. This has been addressed globally through online laboratories [6], the potential of which in the context of SDG 4 (on quality education) has been discussed in the literature [7]. Multiple platforms have been set up to address the need for laboratory learning. The EU, for example, uses a platform termed GoLab, which was set up via a consortium of 12 countries [8]. Labster is another application that provides online laboratories for high school students, largely targeting schools in the United States [9]. Similarly, in India, OLabs, funded by the Government of India, has been the primary provider of online laboratories [10]. The platform was established before the advent of COVID-19 to provide low-cost lab access to students, removing the constraints of time and geography. The syllabus of OLabs is compliant with National Council of Educational Research and Training (NCERT) and Central Board of Secondary Education (CBSE) standards, and is the syllabus followed by more than 21,000 central government-approved schools in India. Despite variations in regional boards, it is possible for state examinations boards to use OLabs with minimal modifications.

This study assesses the role of online laboratories in providing laboratory training of students in India during the pandemic. Users of the OLabs platform, which is hosted on the National Knowledge Network, were from all parts of the country. Specifically, the focus was on analyzing the acquisition and behaviour patterns of OLabs platform users before and during COVID-19 using Google Analytics (GA), while trying to answer the following research questions:

- $\quad$ Did OLabs platform usage increase during COVID-19 as compared to pre COVID-19?

- Are there specific OLabs that learners accessed more than others?

- What were user preferences for skill types, such as simulation, animation, theory, etc.?

- Are there patterns in terms of new users vs. returning users?

- Which subjects were most accessed?

- Is there a gender bias in terms of OLabs access?

- $\quad$ Did users have preference for a device type while accessing OLabs?

\section{Literature Review}

Online or virtual labs have existed since before the pandemic, providing affordable and accessible science and technology education. In fact, science, technologies, engineering and maths (STEM) online laboratories have been recognized as an approach to enabling safe and cost-effective exposure to these subjects without the limitations posed by geography or socioeconomic constraints [11]. Lynch and Ghergulescu [12] reviewed existing platforms for virtual online labs such as Go-Lab, which is an online ecosystem collecting online labs for worldwide sources aimed at European primary, secondary, and high school students. The platform allows instructors to build on existing courses, thereby providing an open platform for educational enhancement. Similar virtual learning platforms such as Chemcollective, Open-source Physics, and Random provide virtual chemistry, physics, and mathematics laboratories, respectively. Many of these existing platforms are open source and allow users to build on each other's work.

To mention a few more concrete examples, virtual laboratories have also been employed to teach basic electrical concepts [13], principles of material measurements [14], and engineering in general including the use of augmented reality [15-17]. More complex and specific subjects such as neurosurgery are also supported in this space. Though not exactly a virtual laboratory, Neurosurgery Atlas allows users to access information on neurosurgery. It has been shown that the information on this platform can be used to facilitate an online neurosurgery course [18]. Other universities have addressed the crisis by postponing laboratory courses until the coming academic year and delivering theoretical courses through online interfaces. This is especially true in core science and medicine [19]. In general, virtual laboratories are accepted as a viable alternative to traditional labs in imparting practical skills to students and professionals and have a positive effect on students' learning process [11,20-22]. Virtual learning has also gained greater acceptance, especially 
among STEM students. Naturally, the relevance of such laboratories has become more evident during the COVID-19 crisis and keeping in mind the possibilities to tailor certain aspects of the learning process by these means [23]. However, a complete lack of practical experience may have adverse effects on students, and this will be the first time in recent history that high school students across the world graduate with little or no hands-on lab experience [24].

Using virtual laboratories instead or in combination with wet laboratories also has cognitive advantages [25]. Compared to direct instruction, virtual labs are more engaging [26], and compared to working with real laboratories in virtual laboratories, students can more easily make quick exploratory experiments, and virtual labs can show elements of a system that cannot be seen in reality. Overall, experimental studies show advantages in learning performance for learning from virtual labs over direct instruction and often also over real laboratories [8]. This work, however, also shows that the inquiry process involved in learning from labs should be supported to make it effective. This support can be given by the teacher, but also by providing students with supplemental material like in OLabs or with interactive apps like in Go-Lab. A second caveat is that students need to be prepared with the right prior knowledge before entering the learning stage with virtual labs.

The use of virtual laboratories became necessary when the facilities that sustain such endeavors were not yet in place. For example, an attempt at online chemistry classes in Rio de Janeiro was hampered by the lack of necessary technology (smart phones, tablets, or computers) among students of lower socioeconomic strata, lack of adequate training of the faculty to address the shift in platform and pedagogy, and the limitations of the platform itself. In fact, without significant improvements, the approach would not be a valid substitute for chemistry laboratories [27]. However, an approach based on collaboration by a team of international instructors to facilitate laboratory style learning outside of the traditional platforms was more valued and had better utility [28]. It should be noted that the countries involved in this study were predominantly developed nations where students were more likely to have access to technology. The University of Toronto combined short campus visits and Labster enabled virtual laboratories to convey the necessary physics, chemistry, and biology lab skills to high school students during the pandemic [29].

In India, OLabs has been the key platform of online laboratory access for high school students. The platform has more than 173 science labs, and nearly 10,000 teachers across the country have been trained [30]. Additionally, the platform is entirely free and provides animations, simulations, and questions aimed at providing a deeper theoretical understanding. Due to these benefits, OLabs has an advantage over its alternatives in India. In fact, practical or laboratory exams carry $30 \%$ weightage for science subjects [31]. Earlier studies on OLabs have shown that while OLabs does not entirely replace the classroom experience, it does provide a platform for supplementary learning, allowing users to repeat experiments without any additional cost. This platform also provides a better understanding of the theoretical concepts, and most teachers favored the use of OLabs [32]. The need for reliable technology was also highlighted in previous studies, as teachers correlated the effectiveness of the software to its speed and responsiveness [30].

In general, the literature identifies online learning and virtual laboratories as usable learning interventions that can help students during this time of crisis. To understand the effects of a completely virtual laboratory environment, it is safe to assume virtual laboratories are likely to be a part of future education even after the COVID-19 pandemic [33]. Therefore, it is essential to understand more about their functioning and utility during the pandemic.

While there are reports that virtual labs have been employed by schools, no scientific analysis on their usage during a pandemic situation is available. This study hopes to contribute to the literature by studying how a virtual learning platform like OLabs helped learners during the pandemic. OLabs is an appropriate platform for this study as it is free and easily accessible. This allows students of every economic class to access it. Additionally, given that it caters to CBSE and NCERT syllabi it will be relevant to students all over India, 
thus eliminating any regional or socioeconomic biases from the study. Learner access and registration is free and unlimited for all content, though students need to log in to access some of the simulation content.

Our study paper is structured as follows: first (Section 3), we review OLabs with its key features as it relates to this paper. Then in Section 4, we discuss the study methodology and related studies that have used Google Analytics (GA) for acquisition and behavior of users. Following this, in Section 5, we interpret and discuss research findings presented through statistical data collected by GA. The final Section 6 is about conclusions and future scope of research.

\section{About OLabs-Online Laboratories for Science Experiments}

OLabs for school lab experiments provides the ease and convenience of conducting laboratory experiments online using the internet. Experiments can be done less expensively and efficiently. At present, 173 OLabs in physics, chemistry, and biology are available as an open educational resource on http:/ / www.olabs.edu.in/ (accessed on 13 March 2021). All the labs are available in English and translated to local Indian languages including Hindi, Marathi, and Malayalam. For schools with limited internet usage, an offline version is also available. Typically each lab will have 6 to 8 tabs for different skill types, such as theory, procedure, animation, simulator, video, resources, etc., as shown in Figure 1.

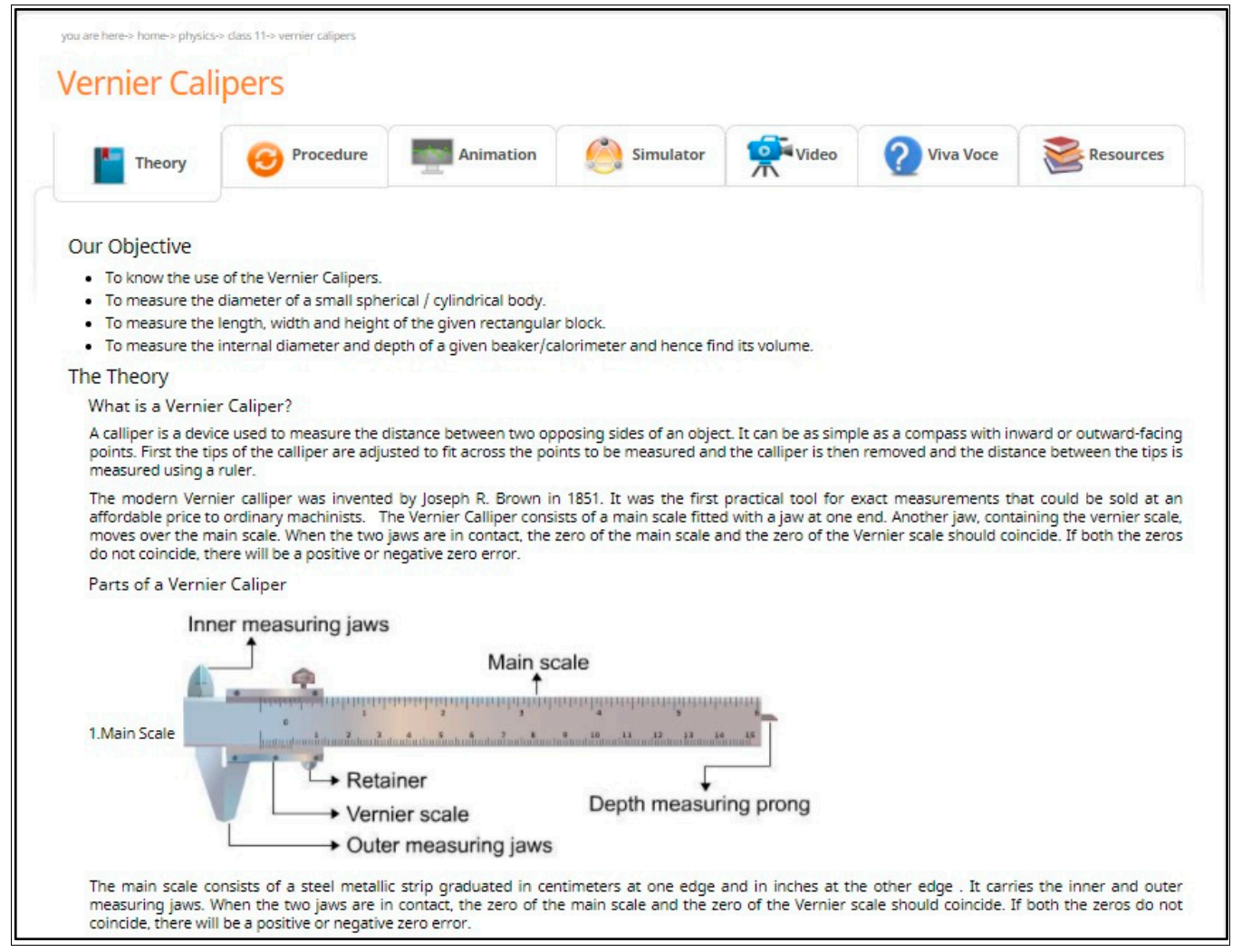

Figure 1. OLabs experiment showing different skill types.

The OLabs platform offers tremendous flexibility for both slow and fast learners. Learners are free to choose any skill type and start their session. Some learners may start directly with simulation to learn by doing, as shown in Figure 2. A typical learner would start with reading about the theory and procedure, then proceed to watch the video with animation, as shown in Figure 3. 


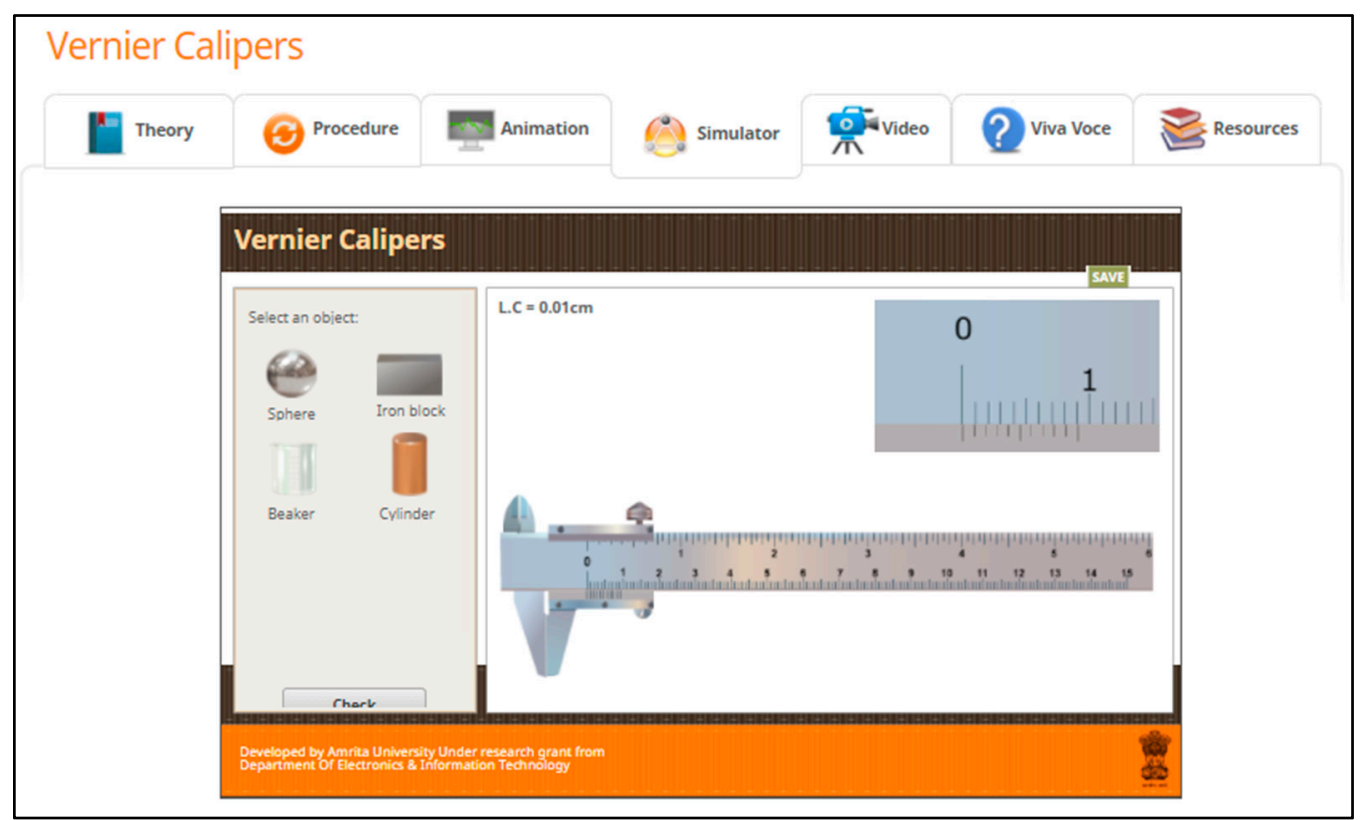

Figure 2. OLabs physics experiment using simulation.

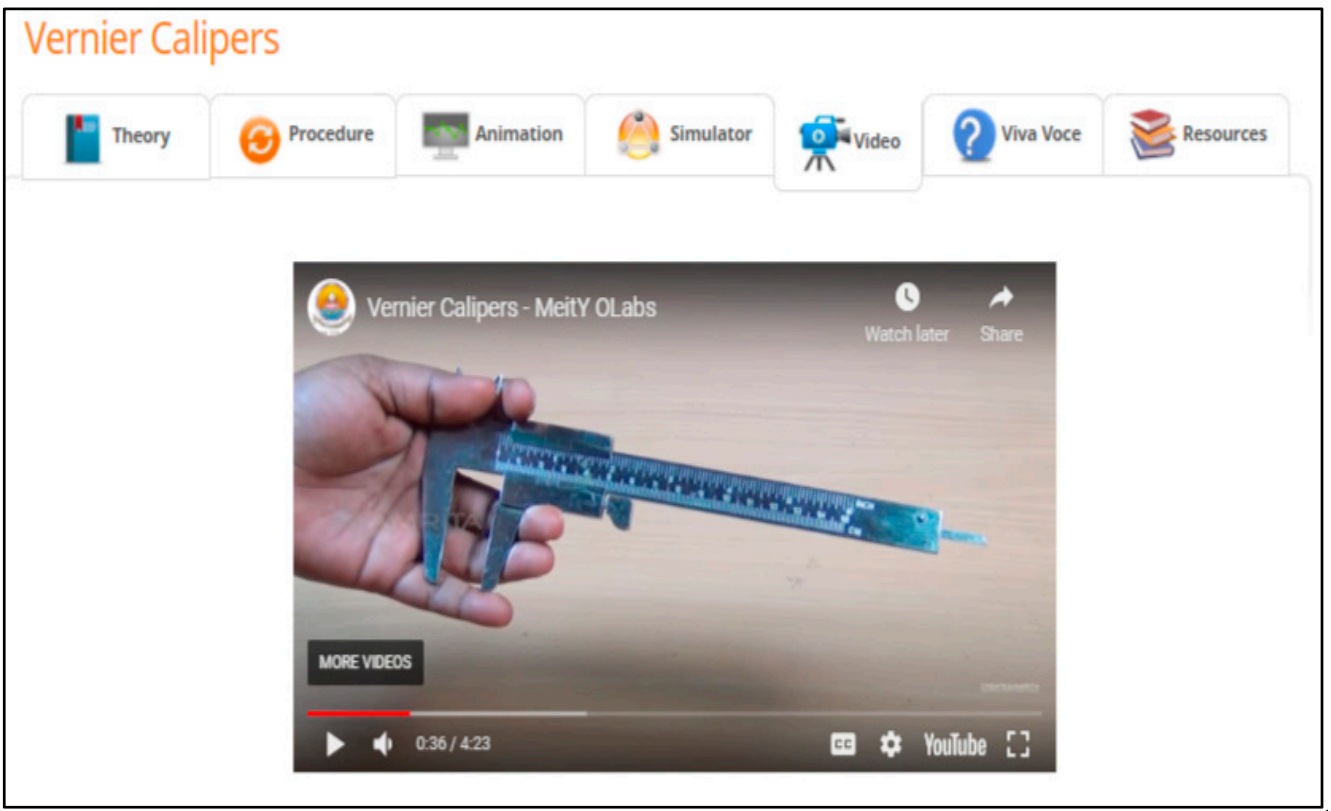

Figure 3. OLabs physics experiment using video.

\section{Study Methodology Using Google Analytics}

Google Analytics was chosen, as it has already been employed for similar analysis in previous studies. For example, Google Analytics data of the Enocta Academic Education Platform (EAEP) were used to analyze user needs and behavior patterns [34]. A similar approach was used to aid teachers in achieving learning goals of students using the eLearning environment Virtual W [35] and online courses [36,37]. Therefore, this paper uses Google Analytics data on OLabs to study how this platform was used during the pandemic to support laboratory education.

Google Analytics provides analytical information about the most viewed pages, number of unique visits per page, the average time spent on a page, the bounce rate, new visitors, and returning visitors used to access the pages and so on $[38,39]$. Google Analytics also provided data on the types of devices used for access. Such information can allow us to consider whether developing a mobile app for OLabs would be helpful or not. The three 
main devices of interest to the current investigation were desktops, tablets, and mobile phones.

Several indicators from Google Analytics that would allow inference of a level of engagement for OLabs were retrieved and analyzed. Selected Google Analytic variables included user behavior, content analysis, how users were acquired, overall website engagement including pages visited per session, bounce rate, utilization rate of specific labs, and user access mode and location, etc.

For our study, Google Analytics usage data from 1 April to 30 December 2019 was retrieved and compared to a similar timeframe in 2020. We called the period April-December 2019 pre-COVID-19 and April-December 2020 the COVID-19 period. We assessed the impact of COVID-19 on school education and usage trends of OLabs between the preCOVID-19 and COVID-19 periods.

\section{Definitions of the Google-Analytics Indicators}

- Pageviews-This indicator specifies the total number of pages viewed, including those viewed by the same user several times.

- Unique Pageviews-This indicator considers the number of unique users who have viewed a page at least once and eliminates users accessing the same page several times.

- Avg. Time on Pages-The average amount of time users spend viewing a specific page.

- Bounce Rate-This shows how many users leave a website after visiting only one page. For example, if you read a single article or page on a website and then leave, this is considered a bounce and is considered when calculating the bounce rate.

- New vs. Returning Visitors-New visitors are individuals that have not engaged with a given website in a particular time, while returning site visitors will have made a minimum of one visit to at least one page of a given site in that duration.

\section{OLabs Analytics-Usage, Skill Type, Subject, Gender, Device}

\subsection{OLabs Platform Usage Trends}

With the advent of lockdown and a greater need for online learning, there has been a marked increase in OLabs usage indicators such as number of users, number of sessions, unique views, and bounce rate, as shown in Figure 4. Overall, the total number of users increased by $93.92 \%$ between April-December 2019 and April-December 2020. The number of new users signing into the platform increased by $90.36 \%$ during the same time frame. The number of sessions went up by $259.18 \%$, showing an increased reliance on online learning. This is in line with expectations, as most schools including government institutions were forced to shift to online teaching starting in March of 2020. Therefore, many new users would have relied on OLabs. Additionally, while OLabs was previously at best a support instrument for education, many teachers would now be inclined to utilize it as a primary teaching resource, thus increasing the number of users as well as number of sessions. This is further illustrated by the increased session time, which went up by more than $53 \%$ and the higher number of sessions per user, which increased by more than $85 \%$.

The genuine nature of this increase is best illustrated by the engagement of users with OLabs. For example, the number of page views increased by $573 \%$ and the number of pages viewed per session increased by more than $87 \%$. Additionally, the bounce rate, which measures the number of times a person enters and leaves a website from the same page without much engagement, dropped by more than $28 \%$. 


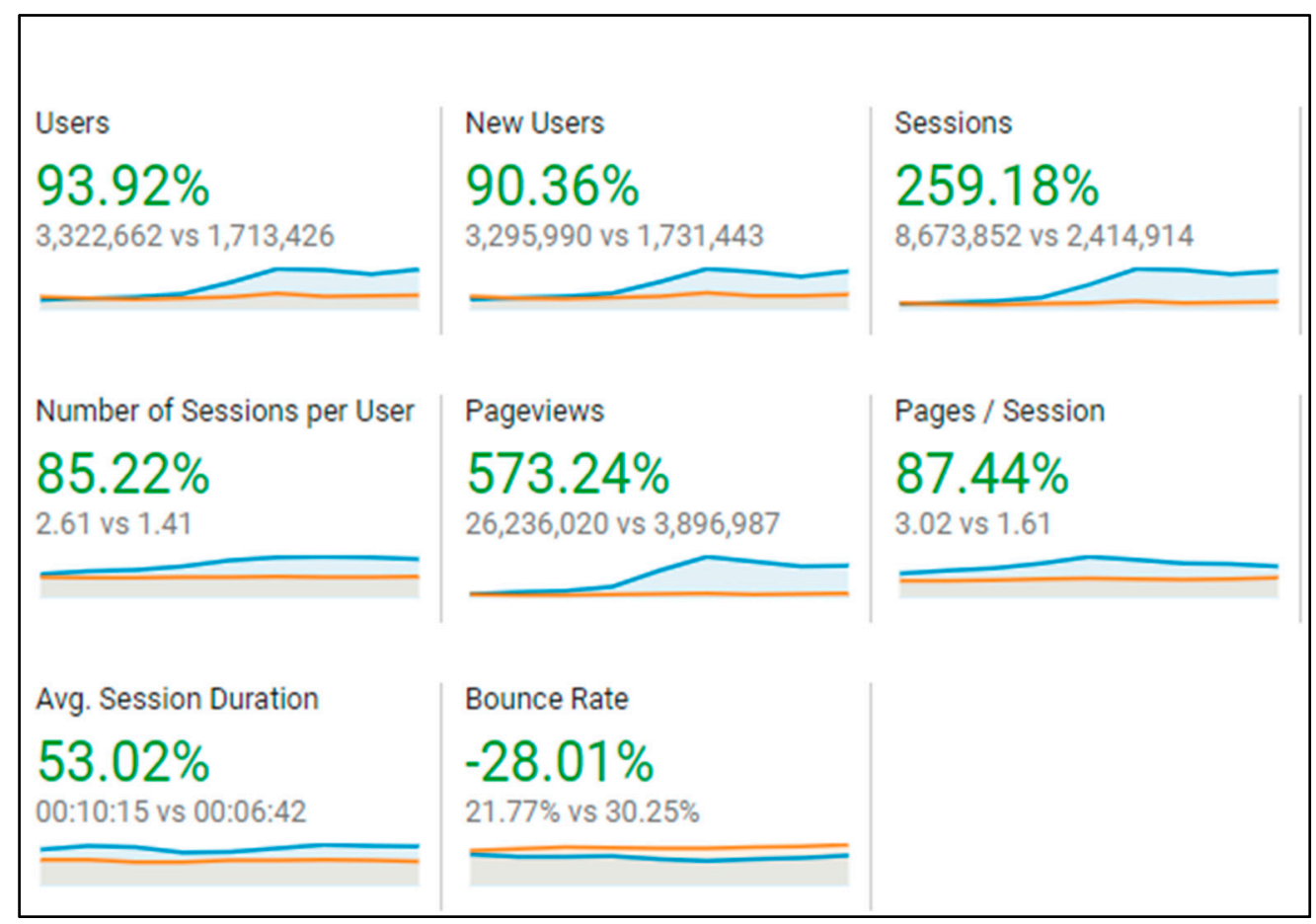

Figure 4. OLabs analytics dashboard comparing April-December 2019 vs. April-December 2020.

During the pandemic year 2020, OLabs platform was accessed by 3 million users. Users increased from a monthly average of 14,908 to 36,700 , with new users increasing from 12,647 to 23,789 , a clear demonstration of the growing visibility and popularity of OLabs, as seen in Figure 5.

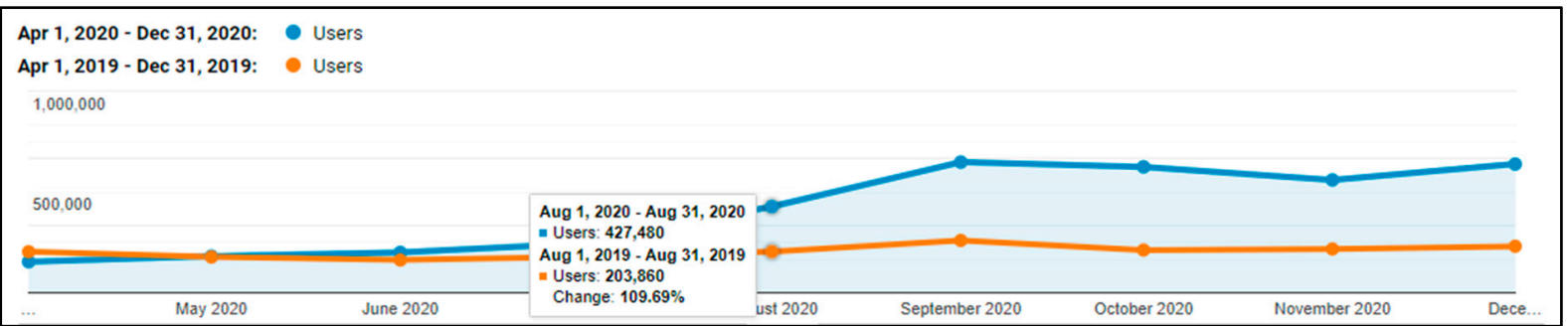

Figure 5. OLabs platform monthly usage comparisons between 1 April 2019-31 December 2019 and 1 April 2020-31 December 2020.

As the data presented above show, the role of OLabs in education has become more prominent during lockdown. This is in line with expectations as online teaching became more popular during the pandemic. By March 2020, India went into a complete lockdown, forcing all educational institutions to move online. This included schools, colleges, and higher-education institutions. Over the span of the next year various lockdowns and restrictions at national and state levels necessitated that most teaching, especially in schools, happened online. Since OLabs is designed specifically with CBSE and NCERT school syllabi in mind, it is natural that many educators and students would have chosen the same for replacing laboratory experimentation. The fact that this platform is free for anyone to use has also contributed to its popularity, especially during the inevitable financial constraints brought about by the pandemic. Therefore, the increase in users and the number of new users is explained.

Overall, it can be inferred that OLabs became more popular during the time of the pandemic, with more learners utilizing the resources, and developing a higher engagement with the platform. 


\subsection{Most Viewed OLabs}

Learners had a preference for labs of certain subjects and within those subjects an inclination to certain skill types, namely theory, simulator, etc., during the COVID-19 period. Labs related to physics (Ohm's law and resistance, Vernier calipers, screw gauge and Vernier calipers) were the most viewed followed by biology (onion and cheek cells) and chemistry (separation of mixtures using different techniques, tests for the functional groups) as observed in Table 1. Learners from class 12 had much higher unique page views, an indication that they were more concerned with school closures and the impending school leaving examinations. While the theory skill type was the most viewed (Ohm's law and resistance), analyzing the count of views for simulators and average time spent on them, an argument can be made that those learners of theories and skill types relating to Ohm's law and resistance and Vernier calipers also used corresponding simulators to reinforce their learnings.

Table 1. Most viewed OLabs as measured by unique pageviews.

\begin{tabular}{|c|c|c|c|c|c|}
\hline Name of the Lab & $\begin{array}{c}\text { Unique } \\
\text { Pageviews }\end{array}$ & Skill Type & Class & Subject & $\begin{array}{c}\text { Avg. Time on } \\
\text { Page }\end{array}$ \\
\hline Ohm's Law and Resistance & 222,798 & Theory & Class 12 & Physics & $00: 02: 25$ \\
\hline Vernier Calipers & 132,498 & Theory & Class 11 & Physics & $00: 04: 23$ \\
\hline Ohm's Law and Resistance & 124,846 & Simulator & Class 12 & Physics & 00:09:41 \\
\hline Onion and Cheek Cells & 119,411 & Theory & Class 9 & Biology & $00: 05: 24$ \\
\hline Screw Gauge & 119,053 & Theory & Class 11 & Physics & 00:04:38 \\
\hline Vernier Calipers & 107,233 & Simulator & Class 11 & Physics & $00: 13: 32$ \\
\hline $\begin{array}{c}\text { Separation of Mixtures Using Different } \\
\text { Techniques }\end{array}$ & 102,749 & Theory & Class 9 & Chemistry & 00:08:43 \\
\hline Tests for the Functional Groups & 83,675 & Theory & Class 12 & Chemistry & 00:10:31 \\
\hline $\begin{array}{l}\text { Determination of Concentration of } \\
\mathrm{KMnO}_{4} \text { solution }\end{array}$ & 79,440 & Theory & Class 12 & Chemistry & 00:04:23 \\
\hline Decomposition Reaction & 78,108 & Theory & Class 10 & Chemistry & 00:07:08 \\
\hline Screw Gauge (Simulator) & 77,686 & Simulator & Class 11 & Physics & 00:09:09 \\
\hline Study of Pollen Germination & 71,698 & Theory & Class 12 & Biology & 00:02:36 \\
\hline Single Displacement Reaction & 68,641 & Theory & Class 10 & Chemistry & 00:04:40 \\
\hline $\begin{array}{c}\text { Separation of Mixtures Using Different } \\
\text { Techniques }\end{array}$ & 65,523 & Theory & Class 9 & Chemistry & $00: 26: 42$ \\
\hline The Potentiometer: Comparison of EMF & 65,217 & Theory & Class 12 & Physics & 00:03:49 \\
\hline
\end{tabular}

\subsection{Understanding Learner Preferences}

Science labs are an integral part of high school education and access to these labs has been very limited during lockdowns. Hence, user behavior has varied during the COVID19 pandemic. While the OLabs videos and animations explain concepts and demonstrate how to perform the experiments in the physical lab, simulations are interactive virtual experiments that could be used as substitutes for hands-on physical labs. Simulations are highly interactive, and students may repeat them in case of errors.

We observe that visitors overall have spent more time with interactive simulations than watching animations and videos. This is confirmed by the average bounce rate (12.3\%), which is lower in the case of simulations with more unique page views of the simulations (3621.6), as seen in Table 2. Hence, it can be inferred that there is preference for simulations. Nevertheless, this could also be attributed to the fact that, due to school closures during COVID-19, physical lab work was not possible, making simulations the next best choice to learn by doing. 
Table 2. Unique pageviews and average bounce rate.

\begin{tabular}{ccc}
\hline Total Visitors & $\begin{array}{c}\text { Average of Unique } \\
\text { Pageviews }\end{array}$ & Average of Bounce Rate \\
\hline Simulations & 3621.6 & $12.3 \%$ \\
Animations and Video & 1915.5 & $14.0 \%$ \\
\hline
\end{tabular}

\subsection{How Many Visitors Are Returning?}

Another indication on the usefulness of the OLabs platform is based on type of visitors and their preference for skills of a certain type. Both new and returning visitors viewed more simulations when compared with animations and video, though simulations were clearly preferred by returning visitors, as seen in Figure 6 (left). As seen in Figure 6 (right), the bounce rate was lower for simulations when compared with animations and video and these numbers are even lower for returning visitors. This is probably an indication that both types of visitors found the learn-by-doing experience with simulations useful.
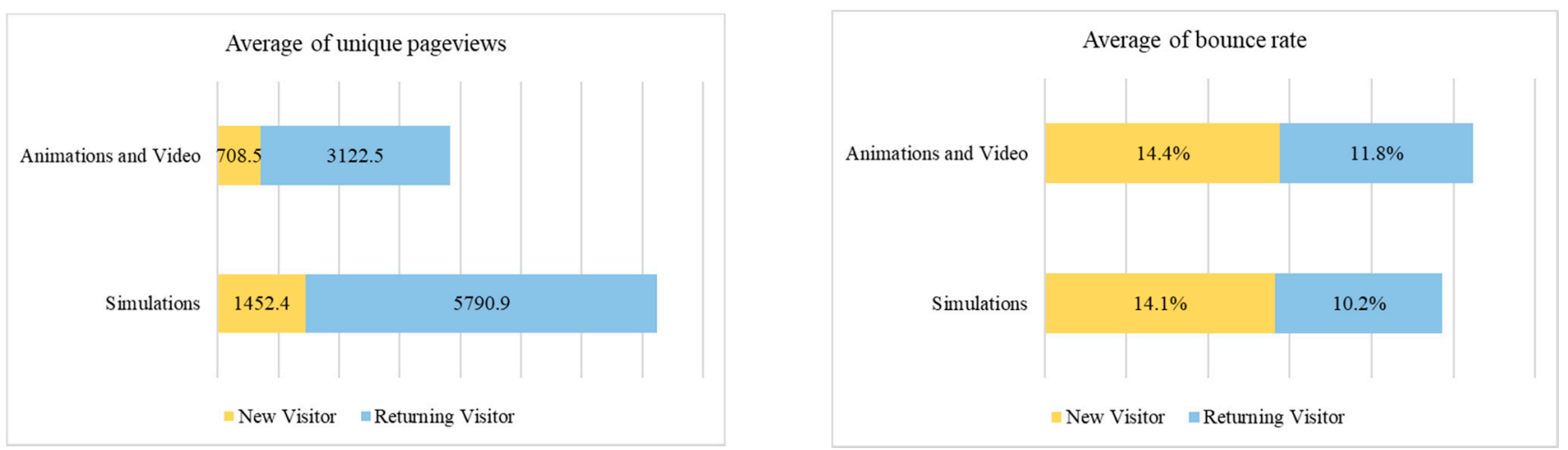

Figure 6. (Left) Unique pageviews (right) and bounce rate for simulations compared to animations and video combined.

\subsection{Top Skill Types Used by Learners}

When data for learners' interest in various skill types is compared, it is encouraging to see that theory had the highest average time $(10 \mathrm{~m} 15 \mathrm{~s})$ spent on a page with highest unique pageviews $(4,823,389)$, as observed in Table 3 . An interpretation of this result could be that the learners start with reading the theory about the experiment and then try out doing the experiment using simulations and finally they explore other skill types, such as procedure, animations, etc.

Table 3. Time spent, bounce rate, and unique views for various skill types.

\begin{tabular}{cccc}
\hline Skill Type & Avg. Time on Page & Avg. of Bounce Rate & Unique Pageviews \\
\hline Theory & $00: 10: 15$ & $19 \%$ & $4,823,389$ \\
Simulation & $00: 09: 29$ & $9 \%$ & $2,124,868$ \\
Procedure & $00: 07: 00$ & $21 \%$ & $1,324,577$ \\
Video & $00: 06: 00$ & $15 \%$ & 473,059 \\
Viva Voce & $00: 04: 01$ & $21 \%$ & 344,163 \\
Animation & $00: 03: 15$ & $11 \%$ & 729,666 \\
Resources & $00: 02: 00$ & $14 \%$ & 119,087 \\
\hline
\end{tabular}

When we compare the two years under study, we observe that the learners showed highest interest in simulations, as indicated by the average time spent on the page $(9 \mathrm{~m}$ 29 s), which also had the lowest bounce rate (9\%), as indicated in Figure 7. Overall, during the pandemic time, the bounce rate decreased across major skill types including simulation, animation, theory and video, which is an indication that due to lockdown, learners spent more time using OLabs resources. 

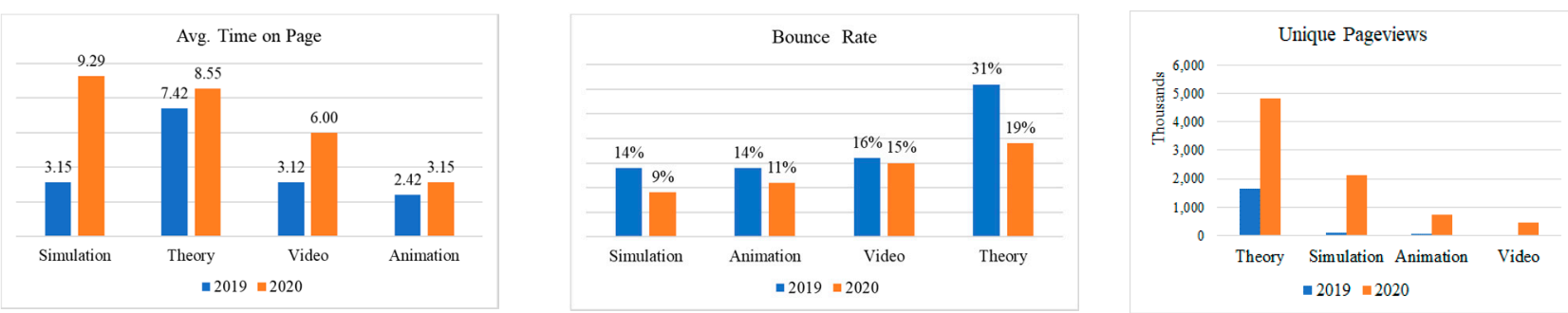

Figure 7. Comparing users' engagement based on skill type between pre-COVID and COVID-19 periods.

\subsection{Most Accessed Content of a Subject by Skill Type}

Analysis of usage patterns of OLabs content based on subjects reveals interesting patterns, as illustrated in Figure 8. The highest unique pageviews were of the theory tab, comprising $48 \%$ of the total unique pageviews. The theory page is the default landing page for a user accessing an experiment from within the website. This was followed by the simulation tab at $23 \%$ but with a much lower bounce rate. Visits to the animation and video tabs together accounted for about $13.1 \%$ of the total views. The resources tab, which provides external material for additional information on the lab, had the lowest level of engagement. This shows that the resources were not used, suggesting that regular users may be getting most of the learning modules within OLabs.

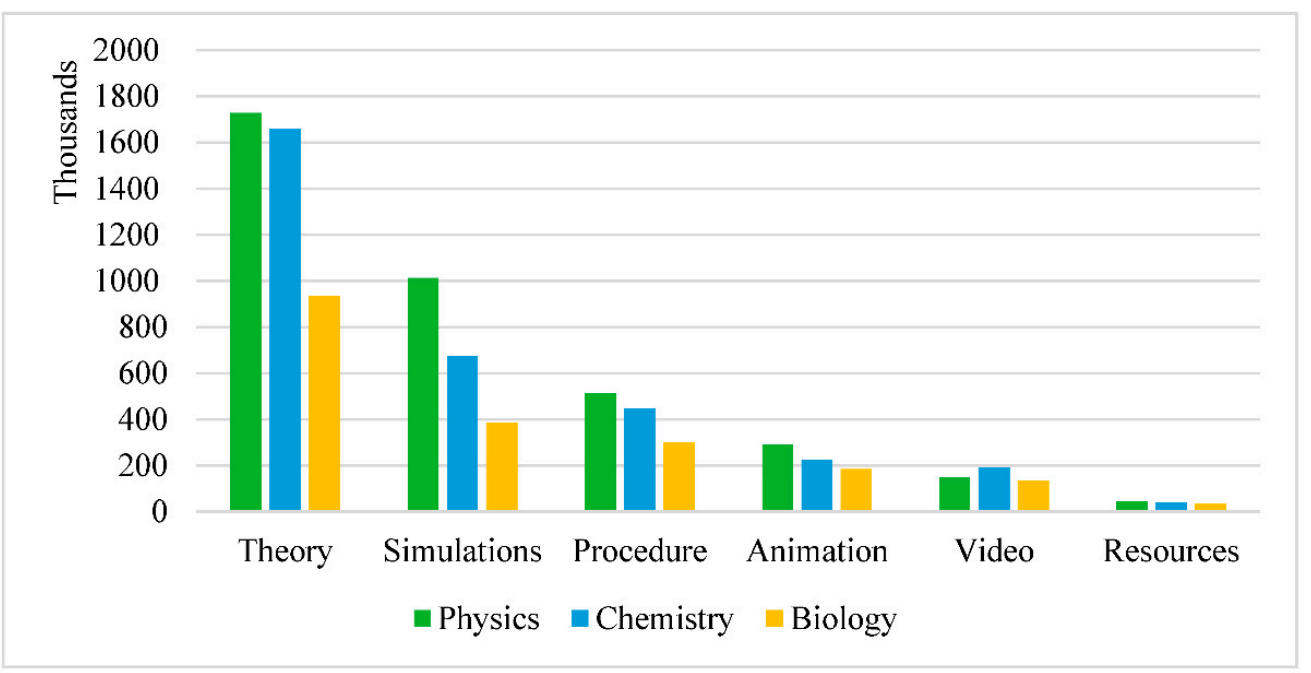

Figure 8. Unique pageviews of skill type based on subjects.

The rich media content consists of animations, videos, and simulations. Most animations and videos are not interactive and designed to understand the underlying concepts and techniques, while the simulations allow for online experimentation. In terms of rich media content, physics had the highest usage in simulations compared with animations and videos put together, followed by chemistry. In biology, considering that many of the experiments are procedural, the simulations were used only slightly more than animations and videos.

The total pageviews for all rich media content, with animation, video, and simulation, were the highest for physics, followed by chemistry and then biology. Students often learned from the procedure page before viewing the animations or performing the simulations. The largest ratio of unique pageviews for procedure vs. simulations and animations was in biology, followed by chemistry and then by physics, suggesting that preference or need to understand the procedure before moving on to simulations and animations was highest in biology and lowest for physics.

Along with the increase in the number of unique pageviews, the average time spent on all subjects also increased during the 2020 pandemic, as observed in Figure 9. For all 
subjects, simulations had the greatest increase in average time spent when compared to the pre-COVID-19 time, suggesting that the students were using simulations as a substitute for physical labs.
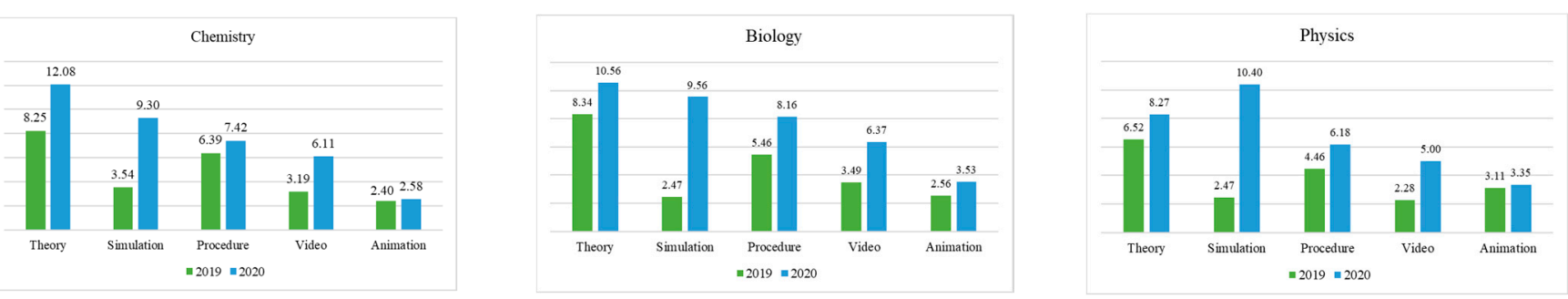

Figure 9. Comparison of average time spent on page by skill type.

The procedure page provides information on using transitional school labs. Interestingly, pre-COVID-19, the pageviews on the procedure and theory were much higher than on the simulation, suggesting that students were learning the procedure and theory as supplementary material to prepare for traditional school labs, whereas during the COVID-19 time, the usage of the simulations was higher than the procedure and theory, suggesting that many students were using the procedure and theory pages to learn to perform simulations.

\subsection{Gender Analysis}

Here we analyzed if the genders behaved differently while accessing different skill types (animation, simulation, theory, etc). In general, a slight variation in gender-based utilization of skill types can be noted, as observed in Figure 10. For example, male learners seemed to slightly favor animation while female learners engaged with simulations and resources. However, the variations were generally minor, and no significant gender bias was observed.

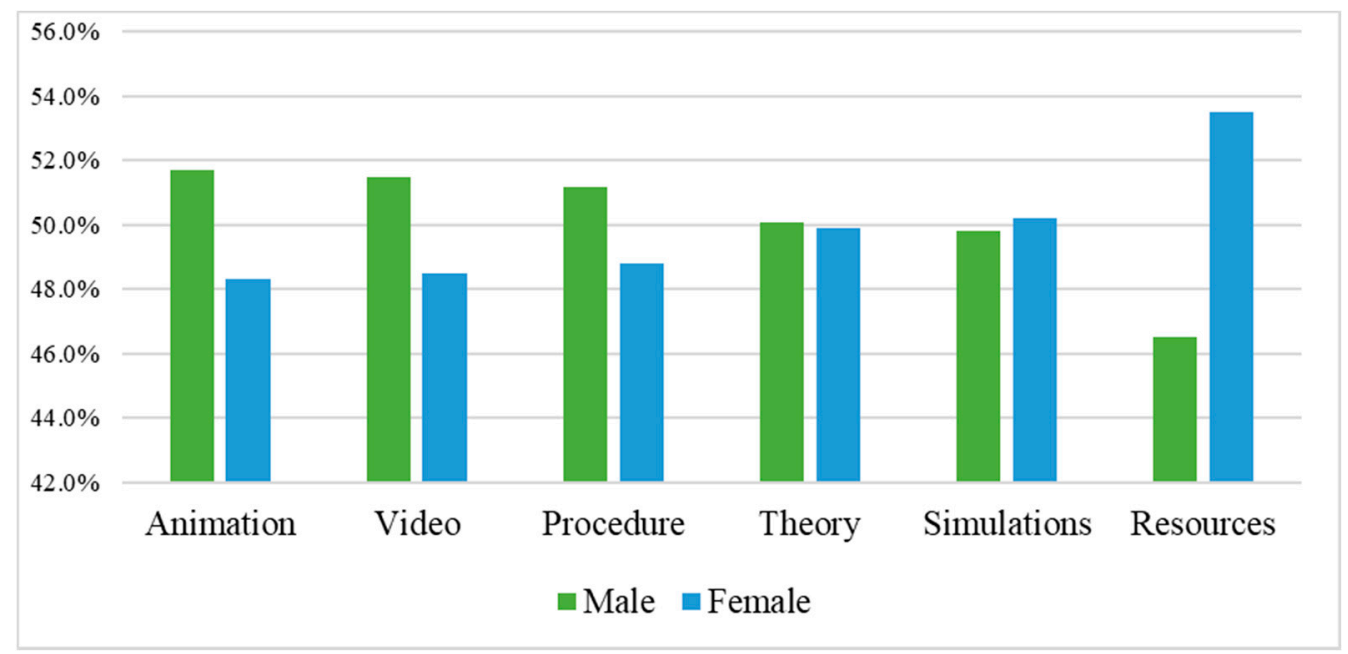

Figure 10. Gender preference for each skill type.

As observed, in Figure 11, male learners had slightly higher unique pageviews (2656.9 vs. 2535.6$)$ and bounce rate $(12.1 \%$ vs. $11.3 \%)$, for simulations, when compared with female learners. Overall, both male and female learners had a preference for the simulations skill type as compared to animation and video. 

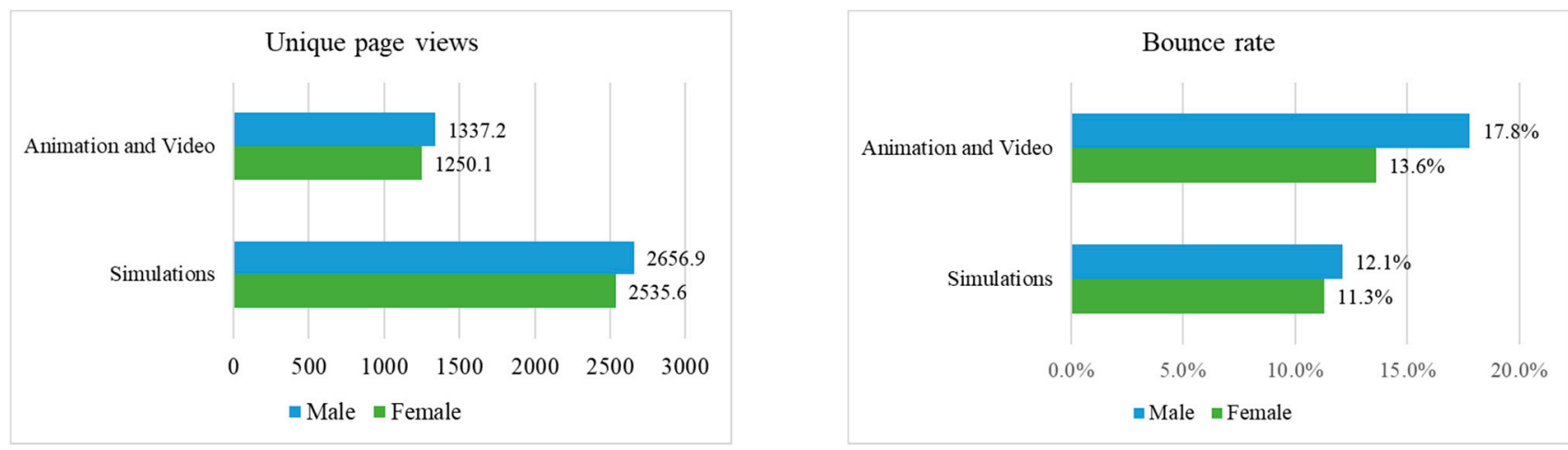

Figure 11. Gender analysis based on unique pageviews and bounce rate for skill type.

\subsection{Content Accessed by Device Type}

Users preferred mobile devices to access content during the COVID-19 time, as seen by the higher number of users and sessions from mobile devices shown in Figure 12. Overall, $65 \%$ of the users accessed the OLabs platform using mobile devices during the pandemic, which is substantially higher compared to the $41 \%$ during the pre-COVID time. One reason could be due to sharing of mobile devices with learners by parents and siblings.

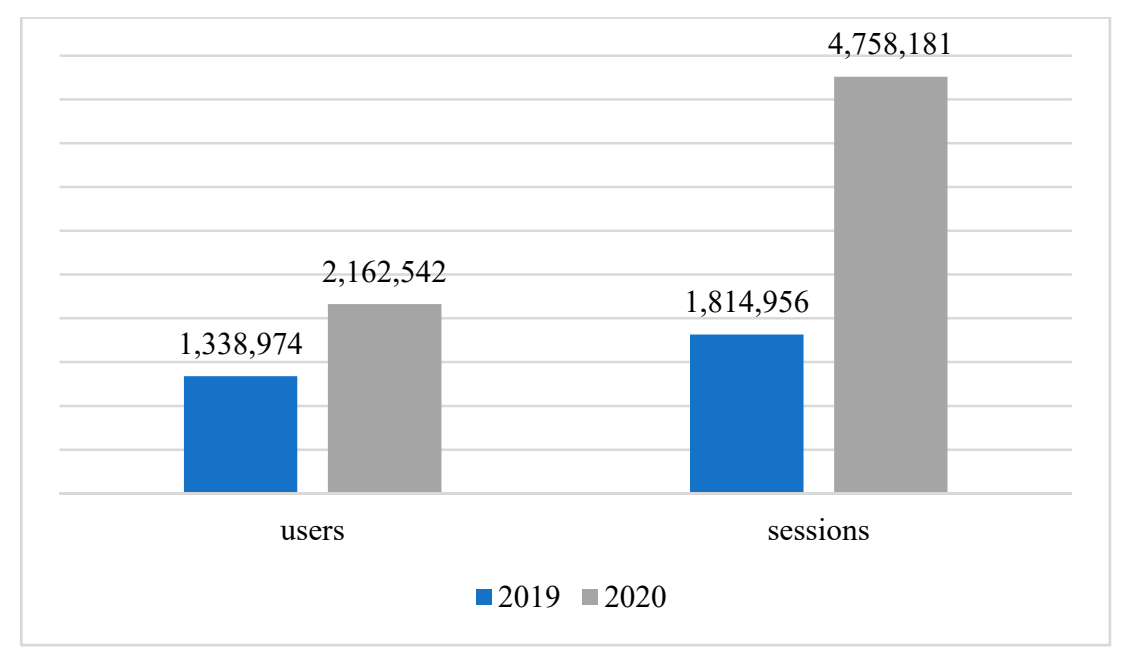

Figure 12. OLabs content accessed by mobile device.

It is, however, important to note that when we compare access by mobile with desktop during the pandemic, the average session duration and pages viewed per session were much higher with a low bounce rate for desktop, as seen in Figure 13. This probably indicates learners' preference for desktops as a learning device for longer study time while mobiles were used for quick access. 


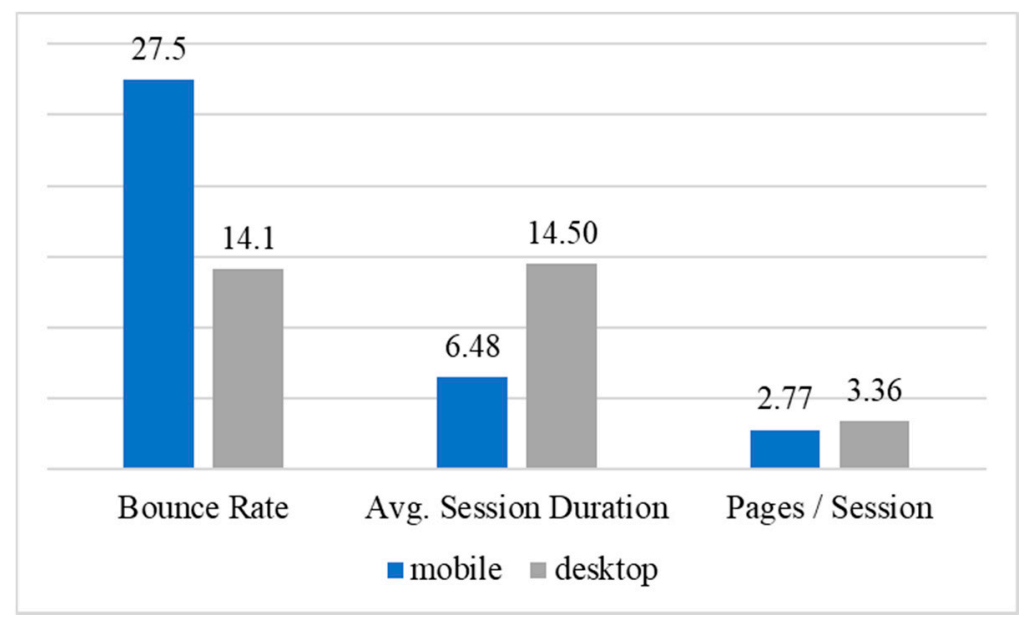

Figure 13. OLabs access comparison between mobile and desktop.

\section{Discussion}

Our results first indicate a significant increase of online learning resources after the start of the COVID-19 pandemic. This increase is reflected not only in terms of access numbers, but also when it comes to the time spent on the platform by students. The current pandemic has set up an excellent platform to assess the potential of novel elearning technologies [40], including for instance the potential of augmented-reality (AR) and virtual-reality (VR) methods to enhance teaching, as shown by [17]. Focusing on the time spent on the platform, it is important to note that the increase during the pandemic was observed for all the courses, i.e., chemistry, biology and physics, with very similar results among courses. This suggests that the three topics are similarly suited for novel e-learning approaches. Focusing on the types of activities, the most prominent increase of time spent in the platform was observed in the simulation category, where clearly one can develop a number of illustrative and novel techniques in the context of OLabs. Theory, which traditionally has been one of the most challenging aspects for the students, also exhibited a significant increase across the three courses; this indicates that there is significant potential in using e-learning for improved teaching of theoretical concepts, including support material to enhance the engagement. Interestingly, animation did not show a notable difference after the pandemic, which suggests that this type of resource may not be the most appealing on the OLab platform, perhaps due to the fact that other alternative resources can be found online for this. Despite small differences in gender, we did not observe any bias associated with this in our results.

\section{Conclusions}

Sophisticated virtual-learning platforms with interactivity, animations and simulations and remote-lab connections are finding increased usage during the COVID-19 pandemic [41,42]. According to the Oxford COVID-19 Government Response Tracker (OxCGRT), India had one of the strictest lockdowns during the year 2020. The average monthly stringency score (77.9) was the highest for India for more than nine months in 2020. There was complete closure of educational institutions with researchers having very limited access to physical labs to perform experiments [43,44].

While OLabs has been used as a support tool for school education, as with many online learning platforms, its utility has increased significantly during the pandemic as laboratory experimentation in schools could not be conducted due to lockdown restrictions. School teachers are being trained to conduct experiments online using OLabs with emphasis on the teacher's role in facilitating active student engagement with the content and with each other. In line with the National Education Policy 2020 from the Government of India, OLabs will allow for all students to have equal access to quality practical and hands-on experiment-based learning experiences. 
The effectiveness of the OLabs platform is best illustrated by the nature of engagement exhibited by the users. For example, the drop in bounce rate indicates that users are willfully using the platform for learning, not leaving after a superficial interaction. The increase in the number of pages viewed per session and an increase in session length show that users are engaging with multiple topics in the same session, spending a longer time engaging in science experiments online. Since no real laboratory work has been possible during the pandemic, it is likely that many schoolteachers and students utilized this platform as an alternative to laboratory experimentation. In general, the results show a greater degree of engagement and utilization of OLabs during the pandemic. This points out that online learning platforms such as OLabs are viewed as viable teaching tools by students and teachers. It also points to the fact that OLabs provides value to these users, as indicated by longer sessions and multiple page engagements.

In a country such as India with relatively high internet penetration and low access to economic resources, a free online laboratory that aids students is of great relevance. This could be part of the reason why user engagement increased during the pandemic, since OLabs is a free platform that could be accessed by students of all socioeconomic strata. Using data obtained from Google Analytics, it is safe to conclude that OLabs and such platforms have a role to play in online education. It is also likely that a portion of users who discovered these platforms due to the lockdown will continue to use them, at least as a support tool even after the pandemic subsides and normal teaching and learning resumes. Additionally, providing free access to information and scientific learning is crucial in a country such as India where students typically have access to limited resources.

Considering the substantially increased usage of OLabs, we have proposed that the Government of India build a new version of OLabs with more than 350 laboratories covering middle school students in new subjects including English and maths. New age technologies such as augmented reality (AR) and virtual reality (VR) will add a new dimension to OLabs. Select OLabs across subjects and grade levels will have an AR/VR component and we will further study their efficacy. We also intend to build OLabs that are aligned with the Indian Sign Language (ISL) standards for use by students with hearing impairment.

Author Contributions: Conceptualization, R.R.; methodology, P.N.; software, P.N.; validation, R.R. and P.N.; data curation, R.R.; writing-original draft preparation, R.R. and P.N.; writing-review and editing, R.V. and P.N.; visualization, R.R. All authors have read and agreed to the published version of the manuscript.

Funding: This research received no external funding.

Data Availability Statement: All data are included in the manuscript itself.

Acknowledgments: This work derived direction and ideas from the Chancellor of Amrita Vishwa Vidyapeetham, Mata Amritanandamayi Devi.

Conflicts of Interest: The authors declare no conflict of interest.

\section{References}

1. Pant, A.; Scott, S.; Nguyen, P.H. How to Support Students and the Learning Process during India's Covid-19 School Closures. 2020. Available online: https:/ / www.ifpri.org/blog/how-support-students-and-learning-process-during-indias-covid-19-schoolclosures (accessed on 7 January 2021).

2. ICEF. With 9 in 10 Students Affected by Covid-19 Closures, How Is the Shift to Online Going So Far? 2020. Available online: https: // monitor.icef.com/2020/04/with-9-in-10-students-affected-by-covid-19-closures-how-is-the-shift-to-online-going-so-far/ (accessed on 7 January 2021).

3. Aristovnik, A.; Keržič, D.; Ravšelj, D.; Tomaževič, N.; Umek, L. Impacts of the Covid-19 pandemic on life of higher education students: A global perspective. Sustainability 2020, 12, 8438. [CrossRef]

4. Qazi, A.; Naseer, K.; Qazi, J.; AlSalman, H.; Naseem, U.; Yang, S.; Hardaker, G.; Gumaei, A. Conventional to online education during Covid-19 pandemic: Do develop and underdeveloped nations cope alike. Child. Youth Serv. Rev. 2020, 119, 105582. [CrossRef] [PubMed] 
5. Nair, S. Online Education Has a Mountain of Problems in India, but It Can Become Accessible, Inclusive If States Are More Proactive-India News, Firstpost. 2020. Available online: https://www.firstpost.com/india/online-education-has-a-mountainof-problems-in-india-but-it-can-become-accessible-inclusive-if-states-are-more-proactive-8571541.html (accessed on 7 January 2021).

6. Pennisi, E. During the Pandemic, Students Do Field and Lab Work Without Leaving Home. 2020. Available online: https: / / www.sciencemag.org/news/2020/07/during-pandemic-students-do-field-and-lab-work-without-leaving-home (accessed on 7 January 2021).

7. Vinuesa, R.; Azizpour, H.; Leite, I.; Balaam, M.; Dignum, V.; Domisch, S.; Felländer, A.; Langhans, S.D.; Tegmark, M.; Nerini, F.F. The role of artificial intelligence in achieving the Sustainable Development Goals. Nat. Commun. 2020, 11, 233. [CrossRef] [PubMed]

8. de Jong, T. The guided inquiry learning principle in multimedia learning. In The Cambridge Handbook of Multimedia Learning, 3rd ed.; Mayer, R.E., Fiorella, L., Eds.; Cambridge University Press: Cambridge, UK, 2005.

9. Thisgaard, M.; Makransky, G. Virtual learning simulations in high school: Effects on cognitive and non-cognitive outcomes and implications on the development of STEM academic and career choice. Front. Psychol. 2017, 8, 805. [CrossRef] [PubMed]

10. Nedungadi, P.; Malini, P.; Raman, R. Inquiry based learning pedagogy for chemistry practical experiments using OLabs. In Advances in Intelligent Informatics; Springer: Cham, Switzerland, 2015; pp. 633-642.

11. Stegman, M.A. Comment on Zacharia et al., A review of data about effectiveness of guidance in computer supported, inquiry based learning laboratories and simulations. Educ. Technol. Res. Dev. 2021, 69, 259-262. [CrossRef]

12. Lynch, T.; Ghergulescu, I. Review of virtual labs as the emerging technologies for teaching STEM subjects. In Proceedings of the INTED2017 11th International Technology Education Development Conference, Valencia, Spain, 6-8 March 2017; pp. 6082-6091.

13. Gunawan, G.; Harjono, A.; Sahidu, H.; Herayanti, L. Virtual laboratory to improve students' problem-solving skills on electricity concept. J. Pendidik. IPA Indones. 2017, 6, 257-264. [CrossRef]

14. Jannati, E.D.; Setiawan, A.; Siahaan, P.; Rochman, C. Virtual laboratory learning media development to improve science literacy skills of mechanical engineering students on basic physics concept of material measurement. J. Phys. Conf. Ser. 2018, 1013, 012061. [CrossRef]

15. Available online: http://kth.diva-portal.org/smash/record.jsf?pid=diva2\%3A1424456\&dswid=-3870 (accessed on 12 April 2021 ).

16. Ramírez, J.; Soto, D.; López, S.; Akroyd, J.; Nurkowski, D.; Botero, M.L.; Bianco, N.; Brownbridge, G.; Kraft, M.; Molina, A. A virtual laboratory to support chemical reaction engineering courses using real-life problems and industrial software. Educ. Chem. Eng. 2020, 33, 36-44. [CrossRef]

17. Hedenqvist, C.; Romero, M.; Vinuesa, R. Improving the Learning of Mechanics through Augmented Reality. Technol. Knowl. Learn. 2021, 1-22. [CrossRef]

18. Davidson, B.; Alotaibi, N.M.; Hendricks, B.K.; Cohen-Gadol, A.A. Popularity of online multimedia educational resources in neurosurgery: Insights from The Neurosurgical Atlas project. J. Surg. Educ. 2018, 75, 1615-1623. [CrossRef]

19. Amir, L.; Tanti, I.; Maharani, D.A.; Wimardhani, Y.; Julia, V.; Sulijaya, B.; Puspitawati, R. Student Perspective of Classroom and Distance Learning Method During Covid-19 Pandemic in The Undergraduate Dental Study Program. BMC Med. Educ. 2020, 20, 392. [CrossRef] [PubMed]

20. Achuthan, K.; Nedungadi, P.; Kolil, V.; Diwakar, S.; Raman, R. Innovation Adoption and Diffusion of Virtual Laboratories; International Association of Online Engineering: Wien, Austria, 2020.

21. De Jong, T.; Linn, M.C.; Zacharia, Z.C. Physical and virtual laboratories in science and engineering education. Science 2013, 340, 305-308. [CrossRef] [PubMed]

22. Ma, J.; Nickerson, J.V. Hands-on, simulated, and remote laboratories: A comparative literature review. ACM Comput. Surv. (CSUR) 2006, 38, 7-es. [CrossRef]

23. Zhai, X. Advancing automatic guidance in virtual science inquiry: From ease of use to personalization. Educ. Technol. Res. Dev. 2021, 69, 255-258. [CrossRef]

24. India Today Web. From Lab Work to Placements: How Graduating Students Can Deal with Covid-19 Lockdown Crisis. 2020. Available online: https:/ / www.indiatoday.in/education-today / featurephilia/story/covid-19-lockdown-how-graduatingstudents-can-deal-with-year-end-crisis-1669087-2020-04-20 (accessed on 7 January 2021).

25. Menon, R.; Sridharan, A.; Sankar, S.; Gutjahr, G.; Chithra, V.V.; Nedungadi, P. Transforming attitudes to science in rural India through activity based learning. AIP Conf. Proc. 2021, 2336, 040003.

26. Haridas, M.; Nedungadi, P.; Raman, R. Incorporating CTML principles in tablet-based learning. In Proceedings of the 2017 International Conference on Technological Advancements in Power and Energy (TAP Energy), Kollam, India, 21-23 December 2017; pp. 1-6.

27. Soares, R.; de Mello, M.C.S.; da Silva, C.M.; Machado, W.; Arbilla, G. Online Chemistry Education Challenges for Rio de Janeiro Students during the Covid-19 Pandemic. J. Chem. Educ. 2020, 97, 3396-3399. [CrossRef]

28. Campbell, C.D.; Challen, B.; Turner, K.L.; Stewart, M.I. \#DryLabs20: A New Global Collaborative Network to Consider and Address the Challenges of Laboratory Teaching with the Challenges of Covid-19. J. Chem. Educ. 2020, 97, 3023-3027.

29. Callaghan, N.I.; Khaira, S.; Ouyang, A.; Cadavid, J.L.; Chang, H.H.; Diep, P.; Ivanov, N.; Li, G.; Li, N.T.; Tran-Nguyen, N.; et al. Discovery: Virtual Implementation of Inquiry-Based Remote Learning for Secondary STEM Students During the Covid-19 Pandemic. Biomed. Eng. Educ. 2020, 1, 87-94. [CrossRef] 
30. Chandrashekhar, P.; Prabhakaran, M.; Gutjahr, G.; Raman, R.; Nedungadi, P. Teacher Perception of OLabs Pedagogy. In Fourth International Congress on Information and Communication Technology; Springer: Singapore, 2020; pp. 419-426.

31. ZeeBiz. CBSE 2021 Exam: Big Changes in Class 12 Question Paper Pattern, Check Details Here. 2020. Available online: https: / www.zeebiz.com/education/news-cbse-2021-exam-big-changes-in-class-12-question-paper-pattern-check-detailshere-141494 (accessed on 7 January 2021).

32. Prabhakaran, M.; Pantina, C.; Gutjahr, G.; Raman, R.; Nedungadi, P. Effectiveness of Online Labs Teacher Training Workshop. In Proceedings of the 2018 IEEE 18th International Conference on Advanced Learning Technologies (ICALT), Mumbai, India, 9-13 July 2018; pp. 249-251.

33. Glassey, J.; Magalhães, F.D. Virtual labs-love them or hate them, they are likely to be used more in the future. Educ. Chem. Eng. 2020, 33, 76-77. [CrossRef]

34. Özen, Z.; Kartal, E.; Emre, İ.E. Analysis of a learning management system by using Google analytics: A case study from Turkey. In Technology Management in Organizational and Societal Contexts; IGI Global: Hershey, PA, USA, 2018; pp. 198-220.

35. Benito, J.C.; García-Peñalvo, F.J.; Therón, R.; Maderuelo, C.; Pérez-Blanco, J.S.; Zazo, H.; Martín-Suárez, A. Using software architectures to retrieve interaction information in eLearning environments. In Proceedings of the 2014 International Symposium on Computers in Education (SIIE), Logrono, Spain, 12-14 November 2014; pp. 117-120.

36. Luo, H.; Rocco, S.; Schaad, C. Using Google Analytics to understand online learning: A case study of a graduate-level online course. In Proceedings of the 2015 International Conference of Educational Innovation through Technology (EITT), Wuhan, China, 16-18 October 2015; pp. 264-268.

37. Sheu, F.R.; Shih, M. Evaluating NTU's OpenCourseWare project with Google Analytics: User characteristics, course preferences, and usage patterns. Int. Rev. Res. Open Distrib. Learn. 2017, 18, 100-122. [CrossRef]

38. Google Analytics Overview. Data Collection and Management. 2016. Available online: https://www.google.com/analytics/ standard/features / (accessed on 27 June 2017).

39. Google Analytics. Understanding Traffic Sources in Google Analytics. 2017. Available online: http:/ /www.practicalecommerce. com/Understanding-Traffic-Sources-in-Google-Analytics (accessed on 27 June 2017).

40. Dickson-Deane, C. Moving practical learning online. Educ. Technol. Res. Dev. 2021, 69, 235-237. [CrossRef]

41. Raman, R.; Sairam, B.; Veena, G.; Vachharajani, H.; Nedungadi, P. Adoption of online proctored examinations by university students during COVID-19: Innovation diffusion study. Educ. Inf. Technol. 2021, 1-20. [CrossRef]

42. Radhamani, R.; Kumar, D.; Nizar, N.; Achuthan, K.; Nair, B.; Diwakar, S. What virtual laboratory usage tells us about laboratory skill education pre-and post-COVID-19: Focus on usage, behavior, intention and adoption. Educ. Inf. Technol. 2021, 1-19. [CrossRef]

43. Hale, T.; Thomas, B.; Noam, A.; Cameron-Blake, E.; Hallas, L.; Kira, B.; Majumdar, S.; Petherick, A.; Phillips, T.; Tatlow, H.; et al. "Variation in Government Responses to COVID-19" Version 9.0. In Blavatnik School of Government Working Paper; University of Oxford: Oxford, UK, 2020. Available online: www.bsg.ox.ac.uk/COVIDtracker (accessed on 10 December 2020).

44. Raman, R.; Vinuesa, R.; Nedungadi, P. Bibliometric Analysis of SARS, MERS, and COVID-19 Studies from India and Connection to Sustainable Development Goals. Sustainability 2021, 13, 7555. [CrossRef] 